\title{
Public perceptions on Controlled Human Infection Model (CHIM) studies-a qualitative pilot study from South India
}

\author{
Manjulika Vaz ${ }^{1}$ D Olinda Timms ${ }^{1} \cdot$ Avita Rose Johnson $^{2} \cdot$ Rathna Kumari S. $^{2}$. \\ Mala Ramanathan ${ }^{3} \cdot$ Mario Vaz $^{1,4}$
}

Accepted: 11 October 2020 / Published online: 21 October 2020

(c) Monash University 2020

\begin{abstract}
Research using Controlled Human Infection Models is yet to be attempted in India. This study was conducted to understand the perceptions of the lay public and key opinion makers prior to the possible introduction of such studies in the country. 110 respondents from urban and rural Bangalore district were interviewed using qualitative research methods of Focus Group Discussions and In-depth Interviews. The data was analyzed using grounded theory. Safety was a key concern of the lay public, expressed in terms of fear of death. The notion of infecting a healthy volunteer, the possibility of continued effects beyond the study duration and the likelihood of vulnerable populations volunteering solely for monetary benefit, were ethical concerns. Public good outcomes such as effective treatments, targeted vaccines and prevention of diseases was necessary justification for such studies. However, the comprehension of this benefit was not clear among non-medical, non-technical respondents and suggestions to seek alternatives to CHIMs repeatedly arose. There was a great deal of deflection-with each constituency feeling that people other than themselves may be ideally suited as participants. Risk takers, those without dependents, the more health and research literate, financially sound and those with an altruistic bent of mind emerged as possible CHIM volunteers. While widespread awareness and advocacy about CHIM is essential, listening to plural voices is the first step in public engagement in ethically contentious areas. Continued engagement and inclusive deliberative processes are required to redeem the mistrust of the public in research and rebuild faith in regulatory systems.
\end{abstract}

Keywords CHIM - Challenge studies · Human infection studies · India · Public perceptions $\cdot$ Public engagement $\cdot$ Research ethics $\cdot$ Vaccines

Manjulika Vaz

manjulikavaz@sjri.res.in

Extended author information available on the last page of the article 


\section{Introduction}

A CHIM is a 'Controlled Human Infection Model' study in which a well-characterized strain of an infectious disease agent is administered at a controlled dose by a specified route to healthy adult volunteers to evaluate the disease itself, its treatment, or the efficacy of candidate vaccines, among others. CHIM studies can lead to better understanding of the mechanism of infection, pathogenesis of disease, contributing host factors, microbial virulence, treatment protocols and vaccine induced responses; and can evaluate potential vaccines. (Gordon et al. 2017; Gopichandran 2018; WHO 2016). CHIM studies have a varied lexicon and are also known as 'challenge studies' as the body is challenged with a microbial pathogen as part of the research model, and more recently as 'experimental infection' (Langenberg et al. 2019; Todnem et al. 2019).

Animal studies may be inadequate in predicting human responses to interventions. Aided by advances in immunology, functional genomics, microbiomics, pharmacogenetics, pharmacokinetics and pharmacodynamics, a CHIM study has evolved as a new methodology in modern infectious disease research (Balasingham et al. 2014; Porter et al. 2017).

However, only $7 \%$ of CHIM studies are carried out in low, middle income countries (LMIC), where the need for research on infectious diseases and vaccines is higher (Gordon et al. 2017; Elliott et al. 2018; Selgelid and Jamrozik 2018). Further, cross immunity and biological variability in different populations can alter host-pathogen dynamics and response to vaccines, making extrapolations of study results from other populations difficult. Since $20 \%$ of the global infectious disease burden is contributed by India, there is clearly a need for infectious disease research in India and the possible introduction of CHIM, in particular. CHIM studies are currently not done in India. CHIM studies are believed to accelerate vaccine and drug development, making the process efficient and less costly (Balasingam and WilderSmith 2016), a benefit that could be important for India (Gordon et al. 2017; Gopichandran and Kang 2018; Dholakia 2018).

Inadequate infrastructure, training and resources, and the absence of a clear regulatory framework are some of the reasons why CHIM studies are not done in India (Gopichandran and Kang 2018, Timms 2018).

\subsection{Ethical issues with CHIM studies}

The history of atrocities associated with experimentation in humans could be a cause for apprehension with human testing in CHIM. (Pollard et al. 2012) As CHIM studies intentionally infect healthy human volunteers and cause disease, it challenges the bioethical principle of 'primum non nocere' or 'non-maleficence'. Thus, these studies would be viewed differently from human studies that typically evaluate therapeutic interventions (Balasingham et al. 2014; Rose 2018; Johari 2018; Vaz 2018).

At present, CHIM studies are typically conducted in non-endemic, high-income countries where volunteers are usually college students. Apart from difficulties with extrapolations due to the genetic profile and environmental factors, it is ethically 
questionable for a population to be exposed to risk when there is little personal or community benefit. In India, where the understanding of biomedical research itself is low (Vaz 2015), acceptance of a study design that includes purposeful infection and quarantine, could be a challenge. In addition, research participants here are often less educated or socially disadvantaged with poor 'health literacy' (Vaz 2015).

The validity of CHIM studies can be questioned in light of the more pressing need to address the social determinants of health. From a social justice viewpoint, CHIM studies may appear to promote immediate medical/technological solutions over mandates for long-term, sustainable provision of basic human living and environmental conditions that can prevent disease.

The scholarly article by Bambery et al (2016), suggests four requirements for human challenge studies to be ethical '(i) conduct independent expert reviews, including systematic reviews; (ii) ensure a publicly available rationale for the research; (iii) implement measures to protect the public from the spread of infection beyond the research setting; and (iv) develop a new system for compensation for harm' (Bambery et al. 2016).

\subsection{Rationale for this study}

There is scarce empirical bioethical literature currently available in India to guide researchers and research ethics committees in navigating the complex ethical issues of purposefully infecting healthy volunteers. It appears that the central ethical dilemma is of individual risk vs public (public health) benefit. Deliberative public engagement is recommended for policy development in contested ethical areas (Molster et al. 2012). Interactions with the public on biomedical research, benefits of participation, and protective bioethical guidelines and laws is likely to promote social acceptance and empowerment within the community. It is also important that ethics regulations evolve 'bottom up' and are not exclusively 'expert-based' as the latter risks being "one-sided, biased or ideological-thus illegitimate" (Schicktanz et al. 2012). Listening to the voices of the people also ensures that the notion of 'public good' encompasses multiple perspectives and standpoints (London 2002). Key outcomes of public engagement are greater transparency of purpose and procedures, the ability to understand and anticipate problems at individual and societal levels, issues of vulnerability and methods to address them; fears and concerns around risks of participation and trust building between the scientific community and the public. Public engagement can improve people's participation, trust and confidence in the researcher, and understanding of the safeguards in research. Public participation in the development of bioethical guidelines that protect their interests, establishes the public as a key stakeholder in research (Blom and De Vries 2011).

Since CHIM research studies have yet to begin in India, it presents an opportunity to do things differently this time around, creating guidelines, processes and infrastructure in a transparent and inclusive manner, to dispel apprehensions born of past clinical trials, and advance vaccine science in a sustainable, safe and cost-effective manner. This paper is the outcome of a study aimed to engage with the public and local stakeholders on their perceptions of acceptability, concerns and participation 
in CHIM studies, in the Indian context, and thereby influence guidelines to be more people-centered.

\section{Methods}

Qualitative research methods and the Grounded Theory approach (Corbin and Strauss 1990) were used in this exploratory study of public perceptions, to generate insights into this new area of medical research. Focus Group Discussions (FGDs) and In-depth interviews (IDIs) were the methods of data collection. The details are described below.

\subsection{Study setting}

The study was conducted in the urban metropolis of Bengaluru and in the surrounding villages of Bengaluru district. Bengaluru is the fastest-growing Indian metropolis after New Delhi, with an estimated population of 12.34 million in its urban area (as of 2017). About 10\% of residents in Bangalore live in slums. Much of the population growth in Bengaluru is due to migration from other states in India (Bangalore Population 2018). Bengaluru was selected as the study setting as it is the location of the primary study team and is also a hub of biotechnology and clinical research (Pulakkat 2015).

90.94\% of Bangalore district is urban (Census 2011-2019 data), with a small proportion remaining rural. Mugalur village in the Sarjapur Hobli (Cluster), of Anekal Taluk (Administrative Block), Bangalore Urban District, $35 \mathrm{kms}$ from Bangalore city was chosen as the area for collection of rural data. The medical college and the Department of Community Health (ARJ, RK) conduct an outreach/ community health program at that location.

\subsection{Participant selection and participant profile}

Participants were of two types-the general public and key informants. They were selected from Bangalore city and Mugalur village (Anekal block, Bangalore District). Participation was completely voluntary. Participant selection was purposeful and aimed at accessing a cross section of society. The key strata of general public covered were males and females, youth and middle aged, members of the public belonging to specific work categories-college students, Information Technology professionals (Bangalore is the IT hub of the country), un-organized sector workers, and mid-income school teachers in the urban areas and members of women's self-help groups, farmers collectives, community health workers and youth groups in the rural areas. Local contacts were used to identify potential participants. Table 1 provides the number of participants in each category, their age groups and work profiles. FGDs were the method of data collection from the general public as it was more practical to meet them as a group. A focussed, guided discussion also makes lay people more comfortable 
Table 1 Focus Group Discussion (FGD) Participants

\begin{tabular}{lcll}
\hline & $\begin{array}{l}\text { No of participants- } \\
\mathrm{n}=92(\mathrm{M} / \mathrm{F})\end{array}$ & Profile of participants & Age range (years) \\
\hline FGD-Rural-1 & $8(0 / 8)$ & Rural Married women & $26-56$ \\
FGD-Rural -2 & $11(11 / 0)$ & Rural Male Youth & $19-36$ \\
FGD-Rural -3 & $8(8 / 0)$ & Rural Farmers, older male & $25-63$ \\
FGD-Rural -4 & $8(0 / 8)$ & Rural Female Youth & $18-22$ \\
FGD-Rural -5 & $7(0 / 7)$ & Community Health Workers & $33-48$ \\
FGD-Urban-1 & $9(4 / 5)$ & Urban College youth & $18-20$ \\
FGD-Urban-2 & $8(0 / 8)$ & Urban slum dwellers & $21-48$ \\
FGD-Urban-3 & $7(0 / 7)$ & Urban upper middle-class apart- & $37-51$ \\
& & ment dwellers & \\
FGD-Urban-4 & $10(0 / 10)$ & Urban School Teachers & $25-43$ \\
FGD-Urban-5 & $10(4 / 6)$ & Urban College youth & $18-23$ \\
FGD-Urban-6 & $6(6 / 0)$ & Urban daily wage labourers & $35-48$ \\
\hline
\end{tabular}

with sharing, as they are not experts in this area. In addition, decision making among these communities in real life is usually through consultation and discussion.

The FGD participants were between 18 and 56 years. Of the 92 participants, there was nearly equal representation of younger $(<30$ years $)$ and older participants ( $>30$ years). About two thirds were married. Majority of the urban respondents were graduates and post graduates while the rural respondents had completed secondary or higher secondary education. People belonged to different religions and caste groups, though many urban respondents were unwilling to disclose religion and caste. They came from various occupational backgrounds: students, salaried employees or daily wage labourers in urban areas. Most of the rural women were homemakers, while the rural men were farmers or weavers. Many of the urban FGD participants refused to disclose their monthly income. Where reported, income levels between the rural and urban participants were extremely disparate. The socio-economic profile of the rural participants was closer to the urban poor.

Key Informants (KIs) were 18 in all. In the rural area they were people who understood the community, were influencers in decision making and were engaged with community health outreach work. In the urban area, the KIs were those knowledgeable about communicable diseases, infectious disease researchers, ethics committee members and those likely to influence public opinion. They included microbiologists, clinicians, public health workers, social workers, Research Ethics Committee Members, media representatives, lawyers, and human rights activists. KIs were between 30 and 70 years of age. The in-depth interview method was used for this category, as each was an independent professional with recognised expertise. Table 2 has a list of the KIs. 
Table 2 Key Informant profile

\begin{tabular}{cllr}
\hline Rural $(\mathrm{n}=7)$ & & (Years) \\
IDI-R-01 & Community Health Worker & Female & 59 \\
IDI-R-02 & $\begin{array}{l}\text { Accredited Social Health Activist (ASHA), a govern- } \\
\text { ment health worker }\end{array}$ & Female & 28 \\
IDI-R-03 & Panchayat (Village Council) member & Female & 40 \\
IDI-R-04 & School teacher & Male & 34 \\
IDI-R-05 & Panchayat (Village Council) member & Male & 45 \\
IDI-R-06 & Auxiliary Nurse Midwife & Female & 35 \\
IDI-R-07 & Medical officer (Primary Health Centre) & Female & 48 \\
Urban (n=11) & & & \\
IDI-U-01 & Anganwadi (Government child care centre) teacher & Female & 36 \\
IDI-U-02 & Health Activist & Female & 43 \\
IDI-U-03 & Legal expert (Senior Advocate) & Male & 43 \\
IDI-U-04 & Infectious Disease Scientist & Male & 44 \\
IDI-U-05 & Microbiologist (Medical College) & Female & 46 \\
IDI-U-06 & Microbiologist (Commercial) & Male & 55 \\
IDI-U-07 & Institutional Ethics Committee Member-Clinician & Male & 71 \\
IDI-U-08 & Institutional Ethics Committee Member -Lay & Female & 62 \\
IDI-U-09 & Information Technology sector employee & Male & 25 \\
IDI-U-10 & Information Technology sector employee & Male & 26 \\
IDI-U-11 & Journalist & Male & 55 \\
\hline
\end{tabular}

$I D I$ In-Depth Interview, $R$ Rural, $U$ Urban

\subsection{Research team}

The research team included the principal investigator (MV), a social scientist with many years of experience working with communities and qualitative research, an ethicist (OT), two public health researchers (ARJ, RK) and a medical researcher (last author) with many years of experience in epidemiology and social science research. MR is an experienced qualitative researcher and a public health scientist who joined the team at the stage of data analysis and interpretation of data.

\subsection{Data collection}

A Focus Group Discussion Guide was developed, pilot tested and fine-tuned. Prior to the FGD, participants were reassured that the discussion was not aimed at recruiting subjects for CHIM research, but intended to understand their views and opinions, there being no right and wrong answers. The discussions flowed naturally and followed the narratives of the respondents and were not limited by the topic guide. A warm up section of the FGD covered a discussion on medical research and ethics. To trigger the discussion on a CHIM study, a generic case scenario was presented as follows: "A CHIM study involves giving an infectious agent (a carefully identified 
low infective form of a germ) at a controlled dose and controlled conditions to carefully selected healthy adult volunteers. The main reasons to conduct a CHIM study are to understand the exact way that the infection affects humans, human responses and the length for which the germ remains in blood and body fluids...". The three areas of focussed probe included (1) perceptions of benefit and concern, (2) understanding who a potential volunteer could be and the nature of consent needed, (3) issues around compensation and its influence on participation. The last section of the guide focussed on the subject of public good and individual altruism.

The topic guide for the IDIs was similar to that of the FGDs but did not include basic awareness of research and ethics. (Copies of the topic guides are available with the first author).

Data collection was done by RK in the rural areas with MV and ARJ as note takers and was done by MV and ARJ in the urban areas. An audio recorder was used after the respondents' consent. While English was the language of most FGDs and IDIs in urban areas, Kannada, the local language of the region, was used for the rural FGDs and IDIs and the lower socio-economic groups in the urban areas. Between June and September 2018, eleven focussed group discussions (5 rural, 6 urban) and 18 in-depth interviews (7 rural, 11 urban) were completed covering a total of 110 respondents. Data collection continued till data saturation was reached.

\subsection{Data analysis}

Audio recorded data was translated and transcribed into textual documents by an external agency. The transcripts were read by data collectors ARJ and MV for errors in content or meaning. All the data collected were analysed using the qualitative method of grounded theory and constant comparison. Data analysis was an iterative process and began when the first transcript was received. Open inductive coding was done by MV and ARJ, a coding framework was developed consisting of a priori codes (those from the topic guides) and de novo codes (those emerging new from the data) using NVIVO software, Version 9.0. and was an ongoing process. Even when MV and ARJ were coding independently, both researchers would recheck the codes, and modify or add if necessary, to the coding framework. The coding framework is provided in Table 3.

Themes have been delineated and presented in the Results section. All the study team members were involved in mapping the emerging themes into a conceptual model and this followed a reflexive process.

\subsection{Ethical clearance}

The study was designed following the ethical guidelines of the Indian Council of Medical Research. Approval of the study protocol, the subject information sheets and consent forms in English and Kannada was received from the Institutional Ethics Committee of the primary research team's institution. (IEC Study Ref No 157/2018 dated 10th May 2018). After reading and/or discussing the study information sheet, all respondents provided written consent for participation, audio recording and for 


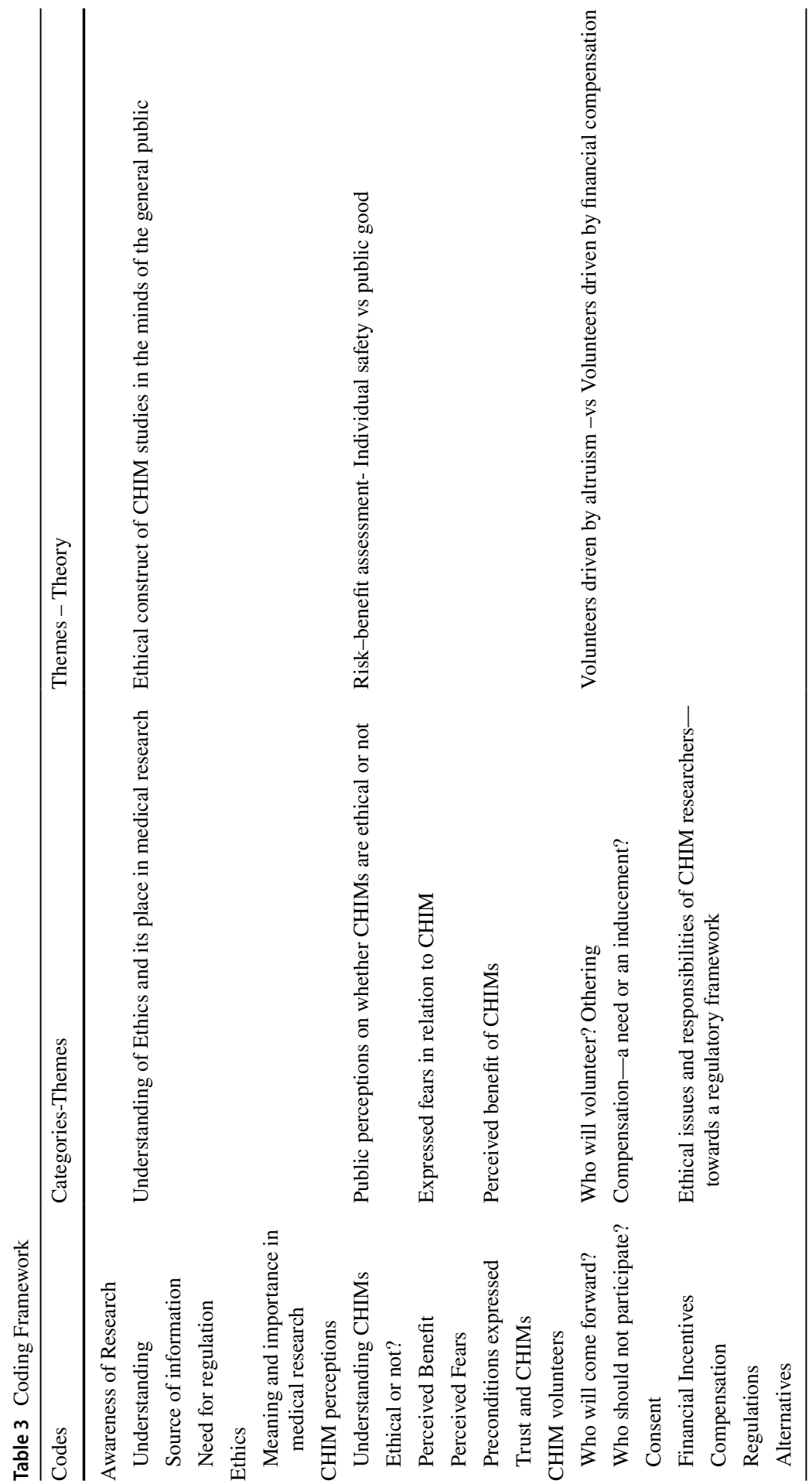


de-identified quotes to be included in publications. Participants were assured of confidentiality, freedom from coercion to speak or participate, and sharing of findings if the participant wished.

\section{Findings}

The perceptions of the general public towards CHIMs have been presented under six major themes (See Fig. 1). Views of the key informants-the health and research experts and the opinion influencers - the media, activists and legal experts have been used to explain the public perceptions or to provide contrasting perspectives.

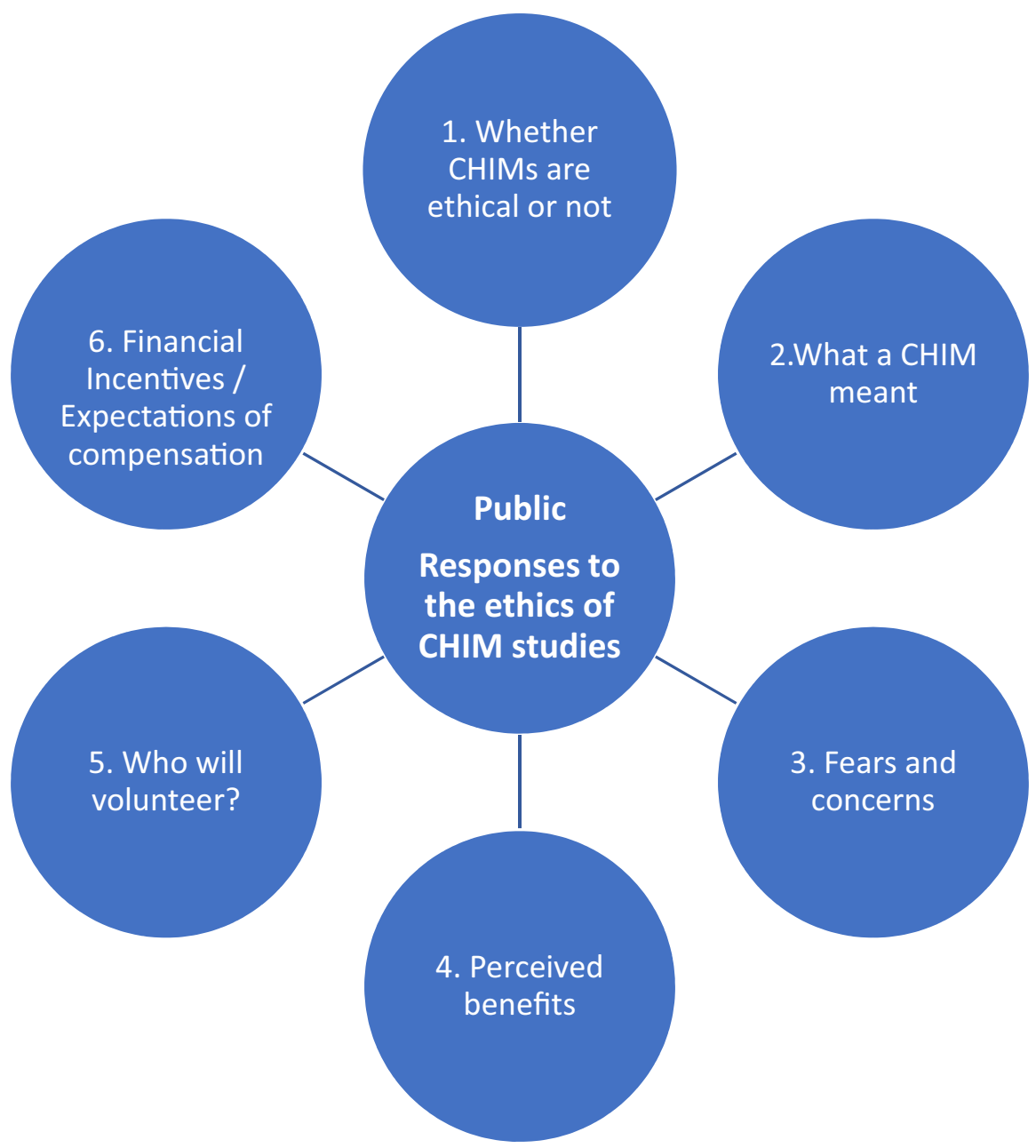

Fig. 1 Six Major Themes 
Illustrative quotes (with affiliation codes) have been provided to support the themes and sub themes. As a backdrop to the perceptions of the public to controlled human infection trials, we have two subsidiary themes-the basic perception of 'research' among the lay public and their perceptions of ethics and its place in research.

\subsection{Lay perceptions about 'research' in general}

There was a clear socio-economic and geographical divide in the understanding of the meaning of research in general. There was less understanding of research among the rural poor. Urban groups and individuals had a clearer understanding-some of the notions they expressed were related to the idea of clinical trials, a focus on 'medicines' and the long timeframe for the outcomes of research to reach the public. The ideas about who did research included 'pharma' companies;

I know that people go through clinical trials ...There are pharmaceutical companies... (Urban FGD 3;);

...there are clinical trials [and] all these various aspects, to ensure it [a drug] is completely safe for the public... ...you realise it is just a preliminary indication and that whatever the benefit to the public, is around 5-6 years later. (Urban-IDI-10).

\subsection{The general public's understanding of 'ethics' and its place in research}

The idea of ethics went beyond medicine and emphasized desired behavior in everyday life. Words that were used to indicate the idea of ethics in the local language included: Sabyatha (decency, civilized), Sampradaya (traditions, spirituality), Maryada (respect, uprightness), Naithika (ethical), Sambanda (relationship with others), Gaurava (honor, prestige), Maanavyamoulya (human values), Ganathe ( dignity),, Vyathiyanadathe (behavior), Naithika Moulya (following ethics), and Siddhantha (principle, tenet) (Ventakatasubbaiah 2012; Asian Educational Services 1999).

In addition to words, understanding of ethics was also expressed in phrases that appeared to be linked to some of the principles of ethics-for instance,

- 'It is about considering others before self' (Urban-FGD 4)-beneficence,

- 'No intentional harm to anyone' (Urban FGD 1)- non-maleficence,

- 'I think ethics is more like moral rights among the people' (Urban FGD 5)autonomy of choice,

- 'We should not underestimate any person or degrade' (Urban FGD 3)_respect and dignity, among others.

Ethics was seen as important in research to reduce harm-'Ethical guidelines should try to avoid collateral damage' (Urban FGD-5); 'medical research team should be confident that there will not be harm to that person' (Rural IDI-1); and, to regulate the processes and purpose of research - 'all the procedures and norms in a proper way'(Urban FGD 4).

They did, however, also identify the gap between intent and practice- 
They [researchers] will concentrate only on research they don't consider anything about ethics (Rural FGD 4); pharmaceutical companies recruit people from poor backgrounds for human trials (Urban FGD 1); commercialization has outgrown the benefit of medical research. (Urban FGD 4).

\subsection{Public perceptions on whether CHIMs are ethical}

A CHIM was seen as ethical if there was a clear benefit. This was echoed across both rural and urban settings.

..I feel it is good if it helps in the prevention of diseases (Rural FGD 3);

We can find the treatment for disease... (Urban FGD 6).

However, many felt that they could not understand the benefit of CHIM clearly. Respondents felt that if CHIM studies had their knowledge base in data from animals it would be more acceptable - this concern seemed to be overwhelmingly about safety.

There was also the strong perception that infecting a healthy person was wrong and that studying the natural course of the disease of an already infected person would be the more ethical, alternative option. An exception was during an epidemic when 'to save those many lives this action should be taken... until then I think this is not required.' (Urban FGD1).

It was also considered important that participation in such studies should be with voluntary consent and with a complete understanding of the study and what it involved. As school teachers in a group discussion said,

It should be [done] voluntarily and it should not be the people who don't understand consequences and just do it for the money...they should have the knowledge and decide on their own. So, it depends on the explanation, ... time and effort taken to explain how it can be done. (FGD-U-4).

The legal expert also cautioned against the enrollment of economically and psychologically vulnerable persons into such studies as it raised ethical and legal suspicions of exploitation. Similarly, the legal position of an individual to voluntarily accept self-harm was perceived as being contentious under the law.

If economically vulnerable strata are subjected to this ... it raises all the wrong alarms... if someone wants to look at a Public Interest Litigation or let us say criminal prosecution... the first question would be to look at psychologically have you misled somebody to self-harm ... (U-IDI-03).

\subsection{What a CHIM meant}

Participants in general had no prior knowledge about CHIM, except for a few key informants who were microbiologists and immunologists. The lay public were able to echo the idea of an infection with a germ, but the extent to which they were able to explain what was communicated to them depended on their education, and prior 
understanding of medical research, among others. One of the questions they raised, important in the context of advocacy for CHIM, was why naturally infected persons were not studied? Another was, while CHIM studies were said to be 'controlled', individual response was likely to be unpredictable, so was it really 'controlled'? Among non-English speaking communities, the word 'controlled' was misunderstood, while health workers associated the word 'control' with 'prevention'.

\subsubsection{Comparisons with clinical trials}

Comparisons with clinical trials were made by key informants with research expertise, who likened the issues of a CHIM study to a phase I clinical trial.

In some ways it is analogous to a phase one clinical trial where you have normal healthy people and give increasing doses of new drugs and study the pharmacokinetics, dynamics, toxicity etc., basically we are doing the same thing except using micro-organisms (Urban IDI-07).

Another similarly trained informant felt that CHIM studies posed less of a risk than drug trials because the infecting agents that were being used were weakened and it was within a controlled (safer) environment.

I think that with a CHIM, germs are being weakened. I think subjects hold a better chance [than a clinical trial]. So, I think the risk factor is slightly less [for CHIM], because it is controlled, the germs are weakened, and it is in a controlled atmosphere. (Urban IDI-08).

\subsection{Fears and concerns in relation to CHIMs}

There were concerns and fears across all age groups and in both the rural and urban areas. Fears appeared to be greater among those least knowledgeable about the idea of CHIMs and less among the more health literate and technical experts. These included:

- Fear of the potential consequences to self and those near and dear

It is highly dangerous, and it involves something ... there are unknown side effects on your body. (Urban FGD-05).

... we are the earning persons for the family, I may be confident enough that nothing will happen but still I have to take care of my family and I should be saved to take care [of them]. Confidence has to be given that nothing will happen to them... (Rural FGD05);

...but what if something happens to my next generation (Urban-IDI -11).

- Fear of something hazardous entering the body where the risk of death was imminent, or the nature of the risk was unknown,

...but when it comes to being infected everyone has second thoughts... (Rural IDI 07).

What if something happens and if I die... (Urban-IDI- 01); 
...it may give negative effects to the brain or it may damage organs... (Rural FGD -05);

We also don't know the long-term repercussions, we actually don't know if the small virus is going to mutate, we want to know what the outcome is (Urban FGD-03);

But what if that remains in our body till, we die (Urban FGD-02);

...we are scared that something might happen, so if it is done on the animals initially it would be good. (Urban IDI-01).

- Fear of exploitation of the socio economically less endowed groups,

... those who are economically less privileged are more likely to take part in a study whether it is risky or not because they really require the benefit that you are providing, that is monetary......not ethical because you are taking advantage of (their) current situation (Urban IDI-09).

- Fear and mistrust of a non-responsive health system in case on long term side effects,

It might be possible that for 6 months nothing will happen and later on it might start reacting in their life, so that has to be taken care of." (Rural FGD-05);

After completion of the research will it create any problems in the future and who do we go to then? (Rural FGD-02);

...there is no guaranteed healthcare, and healthcare not being a standardized thing can be a problem for things that were not diagnosed in that period but later on... (Urban IDI 02);

...the frequency with which some of these things go wrong in the Indian context is much higher... (Urban IDI-04);

What has happened with vaccine research in India in the past has been so murky and it has been unethical. How does one create an ethical study in such an unethical space...? (Urban IDI-02).

When probed if the risk perception would change if the pathogen was known or unknown, health workers in the rural areas gave examples from their own interactions with local communities, where they implied that the facts didn't matter, but perceptions were what influenced responses. One parallel was drawn to methods of family planning that were advocated and another to any health intervention being prescribed, where negative associations were made with what was actually safe.

Among the urban respondents, the IEC lay member felt that it was not about the germ being known but about the perception of danger:

One thing is about a known and unknown pathogen and the other is which is known and known to be ...dangerous... (Urban-IDI 08).

A health activist suggested that people indulge in riskier behaviours in their daily lives - and seemed to suggest that individuals may be overestimating the risk of CHIM- 
...there are so many things that healthy individuals do, there are so many risky behaviours that that healthy individuals indulge in. One cannot say that this is riskier than anything else that you are already doing. (Urban IDI 02).

\subsection{Perceived benefits of CHIMs}

While participants expressed doubts and fears regarding CHIM, they also perceived some benefits of CHIM, primarily in relation to the prevention and treatment of diseases. Some drew parallels with vaccinations 'I feel it is good, it helps in the prevention of diseases... so we can say it is helpful...like we give vaccine to children' (Rural FGD-03), 'the benefits would be in one of two ways, to improve the immune system or to treat similar pathogens' (Urban IDI-09). Perceived benefits were personalised based on how it could help prevent or cure a disease in their own family. At a broader level, the value of the benefit was towards public good, where 'lives could be saved'.

There was a clearer articulation of the benefits of conducting CHIM studies in India among the technically educated, which focused on the opportunity that the method provided to advance science and medical research, relevant to local populations.

What would be the objective of the research, broadly one is to test vaccines because you can expose the person to the infective agent with or without achieving illness, and the second is that it could be used for medical treatment, thirdly it could be used to study the natural course of the infection to know how people will behave with the infections (Urban IDI-07).

...it is not like a conventional vaccine trial where you have to take large number and wait for years for natural incidence in the community, here if you have to do to the challenge [CHIM] method, I can take 100 [volunteers] and I challenge them and I need to follow all hundred and not depend on the natural incidents happening in the community. Another advantage is that we have access to multiple geographies and a very large ethnic diversity in India (Urban IDI06).

...we almost never know what the premorbid state of the individual is, which is something that in the absence of the controlled infection model we have not been able to assess, by the time we get into the picture and start collecting data, especially in the Indian context it is fairly late into the infection. (Urban IDI-04).

\subsection{Who will volunteer to participate in CHIM studies?}

Participants identified people who would likely participate in a CHIM study and included those in need of money, 'risk takers', those who were impulsive, those without dependents or responsibilities, and those with a heightened sense of altruism and social concern. Table 4 provides the details.

In identifying potential participants for a CHIM study, there was a great deal of deflecting-where each group felt that people other than themselves were ideally 
Table 4 Who will volunteer for a CHIM Study?

Perceptions of Urban Participants

- Those who need money

'people who are desperate for money would come for this, but still we should not take that as an advantage and start doing things like this' (Urban FGD-01)

There was also a sense that enrolment of the poor should be avoided for this very reason

- Those who are 'impulsive'

'more impulsive people will be more willing to take this risk, they may be seeking fame...' (Urban IDI 10)

- Those without 'responsibilities'

'Family oriented people, you might find difficult to get as we have responsibilities' (Urban FGD-U 03);

'Might be old aged people who are close to death, if it is younger people and if something happens to them it would be difficult' (Urban FGD-6)
Perceptions of Rural Participants

- Those who need money

'if they are struggling...If they are paid some money ...then they will agree for that' (Rural FGD- 05)

And the contrary position,

'Rich people will not come... because they don't accept anything' (Rural FGD-02)

- Those who were 'risk takers'

- Those without 'responsibilities'

'Old aged people might come. Youth will not agree...If a person who does not have anyone for themselves, who is alone, they might accept' (Rural FGD02);

'People who are alone with no relations might agree for this' (Rural FGD04)

- Those who are altruistic and with heightened social concern

'Whoever has kind heart...' (Rural IDI 02); 'People who think that when we do something it will be benefited to other people in society' (Rural FGD03);

'If social motive is there then people may come forward.... If someone thinks that it will be helpful for others' (Rural-IDI-06)

suited to be participants. It is unclear whether this reflected an underlying fear of a novel method which participants perceived as potentially dangerous.

Participation was determined by the existing knowledge of the infective agent i.e. a priori evidence and treatment options. Another aspect that determined participation was trust; both in individual researchers or medical professionals doing the study, and the overall regulatory environment for support in case of harm.

Depends on the history of the organization ... how they treat patients, how they look at money (Rural IDI 01);

If doctor is giving guarantee that nothing will happen then people will agree. (Urban FGD-6).

Research has to be done, if it is done under the protection of government then it will be good... (Urban FGD-02);

The deflection of the possibility of participation could be indicative of the low levels of trust in individuals and systems for protection of those who are socially and economically vulnerable. Therefore, potential participants identified included those in positions of power and authority; such as gram panchayat (village 
council) members and politicians, or those with the capacity to deal with adverse consequences; such as medical researchers, wealthy or educated persons.

\subsection{Financial incentives/compensation for CHIM participation}

Financial incentives for participation had contrary responses across the spectrum of participants-rural women felt that altruism should be encouraged. In their words, 'Money should never be there in such kind of a trial...', 'Financial incentives would be like a bribe... monetary payments should be avoided, I mean that would then make it into money making thing.'

At the other end of the spectrum, urban male youth took a pragmatic view that participants should be paid-but such payments should not be so large as to induce risk taking. College students were seen as particularly prone to such risk taking —all for a bit of 'pocket money'.

On the other hand, compensation to participants for time and other costs, was acceptable. In order to ensure fairness in compensation, it was suggested to be commensurate with the engagement-in terms of age of the participant, time or wages lost, social status and number of dependents.

Even the urban youth were conscious that such compensation should not become undue inducement; they suggested it should not be mentioned at the recruitment stage to pre-empt this possibility.

...we should not be giving them anything [in the beginning] so that.

will make them real volunteers and in the end, when it is done you can pay

them ... that would become a reward (Urban, FGD 01).

Alternatively, insurance mechanisms that provide not only for persons harmed but for all participants, for a sufficiently long period of time, was also seen as a way of compensation.

\subsection{Towards a regulatory framework}

Although the idea of CHIM was novel to the general public in this study, they identified many ethical issues and specific responsibilities that they believed researchers needed to bear; which could build confidence in people. As specific regulatory guidelines were not yet in place when this study was being conducted, participants' wish list for desired regulations have provided a framework for possible regulations [Refer Fig. 2].

The first issue was the validity of the CHIM method as opposed to alternate research methods, and the choice and safety of the germ, including the availability of suitable treatment-

...let the virus be checked properly before injecting to human being ... check

if it is not harming and there is treatment..., (Rural FGD 02);

Participants were clear that the research team was ultimately responsible for issues related to the participant, 


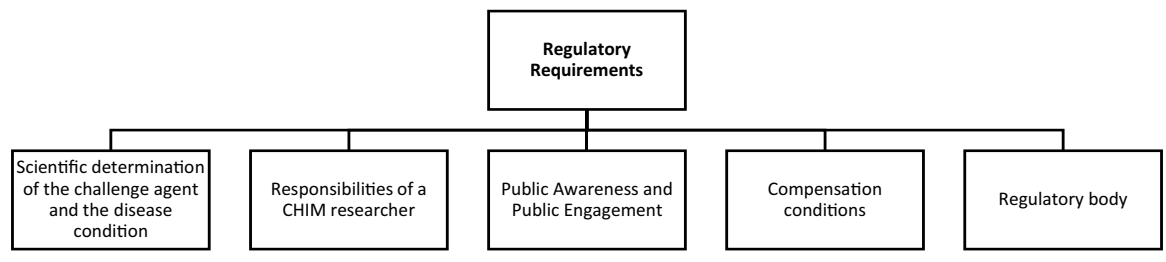

Fig. 2 Towards a Regulatory Framework

In case there is a sudden side reaction or side effects, providing the person with the medical care required. (Urban FGD-05).

...who is doing research must take the responsibility. They should see that nothing will happen to the person who is participating. (Rural FGD-05).

To ensure complete voluntariness of participation and protection of every individual's right to life and free choice, the participant in a CHIM study must do so with a free will, with thorough comprehension of purpose and risks, and without the enticement of financial gain. In the words of a college student,

It is the fundamental right of every healthy human being to reject it if they are scared. (Urban FGD-05).

While consent was unanimously seen as integral to participation in CHIM, the responses obtained indicated that the public see the current system of consent as inadequate-_...it doesn't mean saying yes or putting a thumbprint there... it means they understand what their body will undergo' (Urban FGD-01). The idea of relaying back an understanding of the information received, was a way of testing comprehension.

Assent from a family member was considered an added protection to the participant's informed consent, as there were implications for the family; not only risk and uncertainty but also confined stay in the research facility away from family and work.

Any dependents of the participant, may be a wife or children or parents should give their consent... they should be aware of what the individual is going through (Urban IDI 09).

This was not meant to take away from the autonomy of the individual, as it was emphasized that the ultimate decision lay with the research participant.

The idea of self-harm, even if consented to, appears to be a legal and ethical issue according to the legal expert. There is an underlying perception of having to protect the researcher from legal liability and moral impropriety-

We still need to show objectively from our research that what we're doing is not something shocking to the conscience of public morality. Contracts are void if the intention is self-harm. Sooner or later this can't be left to contract as it must be regulated through legislation. (Urban-IDI-03). 
Complete information was a repeated request. Widespread public interaction and awareness through mass media- television, newspapers and websites were emphasized as a prerequisite, with convincing information about 'the injection', 'why it is given' and 'the benefit that is expected'. Public good and the benefit of disease prevention emerge as a required justification from the public's point of view. Participants believed that widespread media coverage and public discussion of CHIM would ensure greater transparency and more ethical conduct of CHIM. The role of the government in adding credibility to the messaging was also implied. This did not refer to advertisements for recruitment of participants, but an engaged information sharing with the wider public.

Awareness has to be given to people through media like radio and television by government," (Rural FGD-02).

Of importance to the public was the quality of the research, researcher and institution-and these are judgements that people made, at least partly, based on prior knowledge and interactions with people and institutions-

...who is doing the study should take responsibility and should give me confidence... (Rural IDI-01).

Thus, the responsibility of researchers was beyond what routine clinical trials regulations prescribe and should empower volunteers of CHIMs.

The importance of ensuring that the individual was disease and germ free at the end of the study was emphasized as an important regulatory issue, to avoid spread of infections on the one hand, and social ostracization on the other. This was brought up by key respondents through their insights of social and community dynamics.

... they are scared if the subject comes back into the community and infects all of them. So, they might not allow the subject to come back or the second thing is that subject might get ostracized in that area and the future of the children would be stake. (Urban IDI-08).

Several issues emerged in relation to financial transactions during research protocols. Compensation for participation in CHIM protocols was expected to be formulated and mandated by the government. The focus of compensation for injury and inconvenience needed to include the health of the individual not just during the time of the study, but even afterwards. Not only were life insurance and care of family members in case of extreme adverse events required, but health insurance was also advocated. Calculation of compensation was not to be based on who the participant was, but on the risk of the CHIM and the related insurance cover,

Insurance should be more because of the risk. Insurance is compulsory, I think it depends on the risk of the study not on the person who joins the study (Urban FGD-03).

This was however a highly debated issue among community participants.

On the other hand, participants generally agreed that financial incentives to participate needed to be discouraged. 
'Who should regulate these studies?' evoked much interest among the general public, perhaps because such a question was not generally asked of them and it was left to 'people in authority'. There were varied and interesting responses that emerged, ranging from 'the medical team taking full control and being responsible' (Rural FGD-01) to 'a neutral committee with scientists and experts and people from various strata of society... and definitely a few lay people from the public to be involved' (Urban IT Youth-IDI-09). Rural respondents suggested the presence of government representatives on these committees and mentioned 'gram panchayat' (village self-government body) members. There was however some cynicism of having the government as sole regulator of such research.

Not many participants in group discussions were aware of ethics committees and their role in overseeing research in the country. There was some skepticism on the motives of such committees-

We don't know whether ethics committees are there or not in India. We are not aware whether they are doing it for profit, or they are genuinely concerned. They say watch dog but finally it becomes the dog itself. We have various associations, but we don't know how far all this works. (Urban FGD-04).

Experts from the research fields expressed their doubts on whether the present ethics committees in the country would be equipped to handle these additional areas of oversight and monitoring. An ethics committee member as a key respondent in this study had a contrary view, 'Ethics committee do the ground work and ICMR (Indian Council of Medical Research) is the second layer. I think these two regulators are perfectly fine'. A key regulatory requirement would be to ensure that ethics committees are appropriately trained and that an infectious diseases specialist is brought into the review process as an expert.

\section{Discussion}

For Controlled Human Infection studies with its contentious ethical positions, the value of public perceptions in identifying regulatory requirements and researcher responsibilities emerges as critical in the process of ensuring transparency and building trust. Studies in Africa have shown that understanding perceptions of communities on research activities helps in addressing misconceptions, rumours and concerns which can undermine the ethical underpinnings of a well conceptualized study done by credible medical research institutions (Marsh et al. 2008; Gikonyo et al. 2008, Ogobara-Doumbo 2005). For the lay-person in this study, ethics and being 'ethical' went beyond the word and its usage in purely research contexts. Ethics was expected to embody higher virtues of integrity, decency, uprightness, good behavior and relationships with others. This, with the backdrop of people's limited understanding of research, implies that ethical research is not just the way research is done but how it is perceived to be done.

The main messages emerging from this exploration of public perceptions of Controlled Human Infection Model studies in India reflect that, safety is a key concern of the general public with regard to 'being infected' as has already been established 
that the protection of participants is an important concern for CHIMs (Timms 2018). A healthy person 'being infected' purposefully appears unethical. The various fears expressed by the public could be a reaction to the novelty of CHIM and the absence of CHIM studies in India so far.

There was no outright rejection of CHIMs. However, there was an expectation that public good should emerge from such research. Indeed, a clear justification of public good would make such research ethically acceptable.

The disease chosen was expected to have public health relevance to India and it would be desirable if earlier research had been done on animals or humans in other countries.

There was also considerable 'othering' that took place when readiness to participate was explored, with each constituency feeling that people other than themselves may be ideally suited as participants. They created an alternative response to 'the other' than what would be suitable for themselves, thus following a process of 'distantiation' (Brons 2015). By positioning persons unlike oneself as 'others' and giving them characteristics, seen as unacceptable for oneself demonstrates this 'othering' which also reflects existing or perceived unequal relationships (Brons 2015), common in Indian society. The rural folk identified others whom they perceived to be better off than them as potential participants. Urban respondents considered it appropriate for those 'without responsibilities' to volunteer, even the elderly and prisoners. This reflects a utilitarian mindset where the outcome of good for the greatest number makes a certain action acceptable even if it is at the expense of some people i.e. the end justifies the means (Khan 2016).

Those who would willingly volunteer were seen to be the economically poor, who would do so to gain monetary benefit. But this motivation was seen as interfering with the person's ability to discern risk and hence it was recommended that such persons be avoided as participants. It was also the legal opinion that such participation would indicate undue exploitation of the vulnerable.

Comprehension of the procedures and risks emerge as essential pre-requisites for participation. Relaying back the explanation of a CHIM by a potential participant could be a useful means of assessing comprehension. Other methods such as Q\&As and opportunities to discuss concerns and doubts over multiple sittings as suggested in the Kenyan Malaria studies (Njue et al 2018) could be considered. In addition, psychological wellness was an important criterion for a person to assess risks and provide consent.

A gradation of opinion was apparent between the lay public and rural communities on the one side, and health professionals on the other, with the former responding to information provided, while the health professionals and health workers based their responses on their experiences in the field or with similar research. This hierarchy of understanding is dependent not just on education, but technical expertise in research and science. Those with health or medical expertise appear more discerning of the risks, benefits and safeguards in research.

Monetary compensation (seen as a key motivator in the Kenyan Malarial studies-Njue et al. 2018) emerged as a contested area for CHIM studies across all groups and strata of respondents. There was a moral rationale presented, especially in the key informant interviews, for compensation not as cash but as 'care', moving 
the risk-benefit analysis from the immediate to the long term, and from the individual to the family and/or community (third party). It can be argued that in a country like India where comprehensive universal health coverage is absent, a commitment to care can be considered an inducement as well. This, therefore, appears to be a conflicting imperative. However, the duty to care, for the treating physician or the study investigator is an ethical obligation, especially in the context of a CHIM where the intention to harm is a strong perception, with legal implications in India.

These views were also reinforced in recent deliberations on the feasibility and ethics of CHIMs in India, held among wider stakeholders (Vaz et al. 2019), and also from deliberations in other countries such as Vietnam (Kestelyn et al. 2019).

It emerges that in the present context of Indian society (of which this study was a small subset), if such research was to begin, the following would be suitable criteria for selection of participants to such studies:

- Educated persons with reasonable health literacy - for example, science graduates or students, health professionals.

- Persons not in an economically vulnerable situation for whom financial compensation would not be the sole motivation for participation.

- Persons who can not only give free, informed, understood consent, but can also get informed assent from a next of kin or close family member.

It could be argued that these selection criteria perpetuate a paternalistic approach and that all decision making in a liberal democratic society should be autonomous and free. However, Indian culture like that of many other Asian countries, tends to be more communitarian. This is reflected in how respondents described ethical research - "a long term relationship with others", the stated need to obtain assent from family, and the concern of social ostracism following participation. If the protection of potentially vulnerable persons requires paternalistic rules, so as to ensure ethical conduct in the early days of CHIM trials in India, it would be reasonable for regulations to be paternalistic in this regard (Timms 2018). Scholars such as Resnik (2015), support this contention with the reasoning that healthy volunteer participants are not always in a position to understand and assess risk completely, hence need some mechanism, such as a guideline or a committee that can restrict the risk to which healthy volunteers may inadvertently subject themselves to (Resnik 2012).

Public engagement begins at the stage of conceptualizing such a study, by listening to diverse voices across a range of people and proactively understanding the public's fears, concerns and expectations (Vaz et al. 2015; Vaz 2018). The findings of this study highlight areas where public awareness and advocacy are required. The systemic failures of health care delivery, conduct of clinical trials and overall public utilities in India seem to have made the urban, educated sections cynical and wary of government regulation (Bhan 2012). If CHIMs and perhaps any medical research needs to be successful, it needs to begin with an engaged and empowered public (Schicktanz et al. 2012; CIOMS 2016) to develop trust at multiple levels (Gopichandran 2013) — at an individual level of the treating doctor and researcher, since a significant amount of clinical research is done in hospitals and not stand-alone research institutions/contract research organisations; at the level of the institution; and at a 
higher level involving systems related to health delivery and the research regulatory process. The data from the FGDs and urban interviews reveal a great distrust- the practice of medicine itself is seen as a commercial enterprise and medical research as problematic, given the understandings of people about 'unethical research'. Perceptions of ethics emerge based on 'people's lived experiences and the contexts of their lives and not on a preconceived set of ethical principles (McIntosh 2011). Public engagement for CHIM studies is therefore required, not to convince the public to participate in CHIMs or facilitate recruitment but to develop public trust in the system and inform regulatory authorities about perceived areas of contention.

Trustworthiness of the system emerges as an overriding issue. It has three key components in the public engagement paradigm,

- Consultation where listening to diverse opinions is central (Hodgson et al. 2015)

- Collectivism where altruism of the participant is reciprocated by altruism of the researcher in terms of benefit sharing and achieving public good (Molyneux et al. 2012, Vaz et al. 2018, Lairumbi et al. 2012)

- Stake holding, where different players- the lay public, the technical experts, diverse professionals and regulators come together to review regulations and develop contextually appropriate guidelines (Vaz 2018; Vaz et al. 2019)

Regulations that are in the best interest of the public and address areas of mistrust and skepticism, are needed for CHIMs in India (Srinivasan and Johari 2019; Vaz 2018; Vaz et al. 2019). This will help to redeem the poor public image of medical research, clinical trials and ethics committees in India. Regulation that is responsive to public perceptions needs to be widely disseminated (Blom et al. 2011; Vaz 2018). It would be of value to have the public participate in a watchdog neutral body that can question, review, audit and advise the regulator and researcher on the conduct of the study, and also be the eyes and ears for any community repercussions. This could be on the lines of a Community Advisory Board (CAB) that augments the functioning of an institutional ethics committee (Marsh et al. 2008). The CAB's structure and functioning would be mainly to liaise between the community and the researchers, offering a mechanism of contact and mediation. It does not take on the responsibility of recruitment for the study nor is it a gate keeper offering such access. At best, it can be an enabler of responsible decision making. The Institutional Ethics Committee on the other hand has the responsibility of determining risk vs benefit of the study, assessing participant safety and ensuring free and fair participant recruitment.

\section{Conclusion}

At the end of this study, no simple answer emerged to the question of whether India is ready for a CHIM or not; that was not the focus of our enquiry. What it does confirm is that the general public has strong views of safety, expectation of safeguards and ideas of how such research can be regulated. These perceptions not only indicate who are likely to participate in CHIM studies but provide underlying motivations 
and concerns about these studies being ethical or exploitative. Many of the findings that have emerged from this study support the findings of research elsewhere (Marsh et al. 2008, Molyneux et al. 2012, Gordon et al. 2017, Bambery et al. 2016, Njue et al 2018, Kestelyn et al. 2019). As this study was qualitative-we cannot conclude that these represent the views of the public everywhere in India-and there may well be a place for an expanded study across geographies, using a quantitative tool. A more nuanced understanding may also be obtained by presenting specific CHIM scenarios to people and seeking their responses, as was done in a multi-stakeholder workshop in March 2019 where a Malaria, Typhoid and Chikangunya CHIM were discussed (Vaz et al. 2019). In the light of the COVID 19 pandemic and the race to arrive at a safe and efficacious vaccine, additional research in public response to CHIMs in a pandemic and readiness to participate to save lives needs to be explored. What is additionally clear, is that there is a felt need for sustained public engagement, and building awareness and advocacy regarding CHIMs.

Acknowledgements This publication was supported by a grant from the Translational Health Science and Technology Institute (Grant No. 36641644). Its contents are, however, solely the responsibility of the authors and do not necessarily represent the official views of the Translational Health Science and Technology Institute. We acknowledge the time and views shared by the participants of this study and the attendees of the CHIM Pre Congress Workshop of the 14th World Congress of Bioethics 2018, where the findings of this study were shared.

\section{References}

Asian Educational Services. 1999. Kittle Kannada-english dictionary. New Delhi: Asian Educational Services.

Balasingam, S., and A. Wilder-Smith. 2016. Randomized controlled trials for influenza drugs and vaccines: a review of controlled human infection studies. International Journal of Infectious Diseases 49: 18-29.

Balasingam, S., P. Horby, and A. Wilder-Smith. 2014. The potential for a controlled human infection platform in Singapore. Singapore Medical Journal 55 (09): 456-461.

Bambery, B., Selgelid, M., Weijer, C., Savulescu, J., and Pollard, A. J. 2016. Ethical criteria for human challenge studies in infectious diseases. Public Health Ethics 9 (1): 92-103. https://doi.org/10.1093/ phe/phv026. Accessed 07 Apr 2019.

Bhan, A. 2012. Clinical trial ethics in India: one step forward, two steps back. Journal of Pharmacology \& Pharmacotherapeutics 3 (2): 95-97. https://doi.org/10.4103/0976-500X.95501.

Blom, E., and R. De Vries. 2011. Towards local participation in the creation of ethical research guidelines. Indian Journal of Medical Ethics 7: 145-147.

Brons, L.L. 2015. Othering, an analysis. Transcience, a Journal of Global Studies 6 (1): 69-90.

Census 2011-2019 data: Bangalore (Bengaluru) District. https://www.census2011.co.in/census/distr ict/242-bangalore.html. Accessed 5 Mar 2019.

CIOMS 2016. International Ethical Guidelines for Health-related Research Involving Humans, Fourth Edition. Geneva. Council for International Organizations of Medical Sciences (CIOMS). https:// cioms.ch/wp-content/uploads/2017/01/WEB-CIOMS-EthicalGuidelines.pdf. Accessed 17 Aug 2019.

Corbin, J.M., and Strauss, A. 1990. Grounded theory research: Procedures, canons, and evaluative criteria. Qualitative Sociology 13, 3-21. https://doi.org/10.1007/BF00988593. Accessed 30 Sept 2020.

Dholakia, S.Y. 2018. Conducting controlled human infection model studies in India is an ethical obligation. Indian Journal of Medical Ethics 3 (4): 279-285.

Doumbo, O.K. 2005. It takes a village: medical research and ethics in Mali. Science. https://doi. org/10.1126/science.1109773. 
Elliott, A.M., M. Roestenberg, A. Wajja, E. Tukahebwa, et al. 2018. Ethical and scientific considerations on the establishment of a controlled human infection model for schistosomiasis in Uganda: report of a stakeholders' meeting held in Entebbe, Uganda. AAS Open Research 1: 2. https://doi.org/10.12688 /aasopenres.12841.2.

Gikonyo, C., P. Bejon, V. Marsh, and S. Molyneux. 2008. Taking social relationships seriously: lessons learned from the informed consent practices of a vaccine trial on the Kenyan Coast. Social Science \& Medicine 67: 708-720.

Gopichandran, V. 2013. Trust in healthcare: an evolving concept. Indian Journal of Medical Ethics 10: 79-82.

Gopichandran, V. 2018. Controlled human infection models for vaccine development: Zika virus debate. Indian Journal of Medical Ethics 3 (1): 51-55. https://doi.org/10.20529/IJME.2017.093.

Gopichandran, V., and G. Kang. 2018. Controlled human infection models: exploring the landscape in India. Indian Journal of Medical Ethics 3 (4): 270-273. https://doi.org/10.20529/IJME.2018.082.

Gordon, S.B., J. Rylance, A. Luck, Y. Mlombe, et al. 2017. A framework for Controlled Human Infection Model (CHIM) studies in Malawi: report of a Wellcome Trust workshop on CHIM in Low Income Countries held in Blantyre, Malawi. Wellcome Open Research 2: 70. https://doi.org/10.12688/wellc omeopenres.12256.1.

Hodgson, S.H., E. Juma, A. Salim, et al. 2015. Lessons learnt from the first controlled human malaria infection study conducted in Nairobi, Kenya. Malaria Journal 14: 182. https://doi.org/10.1186/ s12936-015-0671-x.

Johari, V. 2018. Law and ethics in consensual harm. Indian Journal of Medical Ethics 3, 292. https:// ijme.in/articles/law-and-ethics-in-consensual-harm/. Accessed 07 Aug 2019.

Kestelyn, E., C. LePhuong, J.I. Van Nuil, et al. 2019. Expert voices and equal partnerships: establishing Controlled Human Infection Models (CHIMs) in Vietnam [version 1; peer review: 3 approved]. Wellcome Open Research 4: 143. https://doi.org/10.12688/wellcomeopenres.15337.1.

Khan, Z.H. 2016. A quest for utilitarian approach in research. Indian Journal of Anaesthesia 60 (1): 6-7. https://doi.org/10.4103/0019-5049.174805.

Lairumbi, G.M., M. Parker, R. Fitzpatrick, and M. English. 2012. Forms of benefit sharing in global health research undertaken in resource poor settings: a qualitative study of stakeholder's views in Kenya. Philosophy, Ethics, and Humanities in Medicine 7: 7-10.

Langenberg, M.C., M. Hoogerwerf, J.J. Janse, L. van Lieshout, P.L. Corstjens, M. Roestenberg, et al. 2019. Katayama syndrome without Schistosoma mansoni eggs. Annals of Internal Medicine 170 (10): 732-733. https://doi.org/10.7326/L18-0438.

London, L. 2002. Ethical oversight of public health research: can rules and IRBs make a difference in developing countries? American Journal of Public Health 92: 1079-1084.

Marsh, V., D. Kamuya, C. Gikonyo, Y. Rowa, and C.S. Molyneux. 2008. Beginning community engagement at a busy biomedical research programme: experiences from KEMRI CGMRC-Wellcome Trust Research Programme, Kilifi. Social Science \& Medicine 67 (5): 721-733.

McIntosh, T. 2011. Maori and cross-cultural research: Criticality, ethicality and generosity [online]. New Zealand Sociology 26, 61-75. https://search.informit.com.au/documentSummary; $\mathrm{dn}=7437091723$ 69596. Accessed 17 Aug 2019.

Molster, C., S. Maxwell, L. Youngs, A. Potts, G. Kyne, F. Hope, et al. 2012. An Australian approach to the policy translation of deliberated citizen perspectives on biobanking. Public Health Genomics 15 : 82-91.

Molyneux, S., S. Mulupi, L. Mbaabu, and V. Marsh. 2012. Benefits and payments for research participants: experiences and views from a research centre on the Kenyan coast. BMC Medical Ethics 13: 13.

Njue, M., P. Njuguna, M.C. Kapulu, et al. 2018. Ethical considerations in Controlled Human Malaria Infection studies in low resource settings: experiences and perceptions of study participants in a malaria Challenge study in Kenya [version 2; referees: 2 approved]. Wellcome Open Research 3: 39. https://doi.org/10.12688/wellcomeopenres.14439.2.

Pollard, A.J., J. Savulescu, J. Oxford, A.V. Hill, et al. 2012. Human microbial challenge: the ultimate animal model. The Lancet Infectious Diseases 12: 903-905. https://doi.org/10.1016/s1473 -3099(12)70292-x.

Bangalore Population. 2018. https://worldpopulationreview.com/world-cities/bangalore/. Accessed 18 Mar 2019.

Porter, C.K., A.L. Bourgeois, R.W. Frenck, M. Prouty, N. Maier, and M.S. Riddle. 2017. Developing and utilizing controlled human models of infection. Vaccine 35: 6813-6818. 
Pulakkat, H. 2015. How Bengaluru became the biotech capital of India. The Economic Times, Nov 2015. https://economictimes.indiatimes.com/industry/healthcare/biotech/healthcare/how-bengaluru-becam e-the-biotech-capital-of-india/articleshow/49751173.cms. Accessed 3 Apr 2019.

Resnik, D.B. 2012. Limits on risks for healthy volunteers in biomedical research. Theoretical Medicine and Bioethics 33 (2): 137-149. https://doi.org/10.1007/s11017-011-9201-1.

Resnik, D.B. 2015. Paternalism and utilitarianism in research with human participants. Health Care Analysis 23 (1): 19-31. https://doi.org/10.1007/s10728-012-0233-0.

Rose, A. 2018. The ethics of volunteer selection and compensation in Controlled Human Infection Models in India. Indian Journal of Medical Ethics 3: 285. https://ijme.in/articles/the-ethics-of-volun teer-selection-and-compensation-in-controlled-human-infection-models-in-india. Accessed 07 Aug 2019.

Schicktanz, S., M. Schweda, and B. Wynne. 2012. The ethics of 'public understanding of ethics'-why and how bioethics expertise should include public and patients' voices. Medicine, Health Care and Philosophy 15: 129-139.

Selgelid, M.J., and E. Jamrozik. 2018. Ethical challenges posed by human infection challenge studies in endemic settings. Indian Journal of Medical Ethics 3 (4): 263-266. https://doi.org/10.20529/ IJME.2018.073.

Srinivasan, S., and V. Johari. 2019. Consultations on human infection studies in India: do people's voices really count? Indian Journal of Medical Ethics 2: 1-6. https://doi.org/10.20529/IJME.2019.011.

Timms, O. 2018. Protecting challenge study participants in low- and middle-income settings. Indian Journal of Medical Ethics 3 (4): 289. https://ijme.in/articles/protecting-challenge-study-participan ts-in-low-and-middle-income-settings/. Accessed 16 Sep 2019.

Todnem, S.S., H. Steinsland, S. Skrede, E. Kleppa, et al. 2019. Experimental infection of human volunteers with the heat-stable enterotoxin-producing enterotoxigenic Escherichia coli strain TW11681. Pathogens 8 (2): E84. https://doi.org/10.3390/pathogens8020084.

Vaz, M. 2018. Public engagement in the context of a CHIM study. Indian Journal of Medical Ethics 3 (4): 296-300. https://doi.org/10.20529/IJME.2018.087.

Vaz, M., M. Vaz, and K. Srinivasan. 2015. Listening to the voices of the general public in India on biomedical research - an exploratory study. Indian Journal of Medical Ethics 12 (2): 68-77.

Vaz, M., Vaz M., and Srinivasan, K. 2018. The views of ethics committee members and medical researchers on the return of individual research results and incidental findings, ownership issues and benefit sharing in biobanking research in a South Indian city. Developing World Bioethics. https://doi. org/10.1111/dewb.12143. Accessed 17 Aug 2019.

Vaz, M., Timms, O., Rose, A., Manesh, A., and Bhan, A. 2019. Consultation on the feasibility and ethics of specific, probable Controlled Human Infection Model study scenarios in India: a report. Indian Journal of Medical Ethics. https://ijme.in/articles/consultation-on-the-feasibility-and-ethics-of-speci fic-probable-controlled-human-infection-model-study-scenarios-in-india-a-report/. Accessed 17 Aug 2019.

Ventakatasubbaiah, G. 2012. Kannada-english dictionary, 1st ed. Bengaluru: IBH Prakashana.

WHO 2016. Expert Committee Report. https://www.who.int/biologicals/expert_committee/Human_chall enge_Trials_IK_final.pdf. Accessed 07 Aug 2019.

Publisher's Note Springer Nature remains neutral with regard to jurisdictional claims in published maps and institutional affiliations.

\section{Affiliations}

\section{Manjulika Vaz ${ }^{1}\left[\right.$. Olinda Timms ${ }^{1} \cdot$ Avita Rose Johnson ${ }^{2} \cdot$ Rathna Kumari S. ${ }^{2}$. Mala Ramanathan ${ }^{3} \cdot$ Mario Vaz $^{1,4}$}

1 Division of Health and Humanities, St John's Research Institute, St John's Medical College, Bangalore 560034, India

2 Department of Community Health, St John's Medical College, Bangalore, India 
3 Achutha Menon Centre for Health Science Studies, Sree Chitra Tirunal Institute for Medical Sciences and Technology Medical College, Thiruvananthapuram, Kerala, India

4 Department of Physiology, St John's Medical College, Bangalore, India 